\title{
Exogenous albumin inhibits sorafenib-induced cytotoxicity in human cancer cell lines
}

\author{
SYU-ICHI KANNO, KATSUYUKI ITOH, NAOTO SUZUKI, AYAKO TOMIZAWA, \\ SHIN YOMOGIDA and MASAAKI ISHIKAWA
}

Department of Clinical Pharmacotherapeutics, Tohoku Pharmaceutical University, Aoba-ku, Sendai 981-8558, Japan

Received May 3, 2012; Accepted June 6, 2012

DOI: $10.3892 / \mathrm{mco} .2012 .3$

\begin{abstract}
Sorafenib is an orally administered multikinase inhibitor that exhibits anti-angiogenic and anti-tumor activity. Sorafenib is also known to bind to protein (>99.5\%), suggesting protein binding may be involved in sorafenib pharmacokinetic variability. Albumin is a major drug-binding protein. In this study, we examined the effect of albumin on sorafenib-induced cytotoxicity using two in vitro culture cell lines, human hepatoma Huh-7 cells and androgen-independent prostate cancer PC-3 cells. The cells were cultured and incubated, and cytotoxicity was assessed. Results were confirmed by western blotting. The presence of exogenous albumin markedly blocked the sorafenib-induced cytotoxicity in the two cell lines. Albumin concentration, the change of pharmacological signal transduction as Raf-B, vascular endothelial growth factor (VEGF), and phosphorylation of MEK1/2 or ERK1/2 were found to be decreased by sorafenib. Co-incubation of warfarin, a representative coumarin anticoagulant and potent binding activity, with albumin enhanced the cytotoxic effects by sorafenib. These mechanisms depend on the high binding properties of sorafenib and exogenous albumin. Furthermore, we investigated the effects of endogenous albumin expression on sorafenib-induced cytotoxicity using the siRNA knockdown system or transfected expression vector assay. However, the cytotoxic effects by sorafenib showed little change either with the knockdown or overexpression of albumin. Our results suggest that particular care should be taken with albuminemia or the combined use of drugs with a high affinity for albumin, such as warfarin, and sorafenib in the treatment of cancer patients. Our findings may be useful to the cancer therapeutic strategy by sorafenib.
\end{abstract}

Correspondence to: Professor Syu-Ichi Kanno, Department of Clinical Pharmacotherapeutics, Tohoku Pharmaceutical University, 4-4-1 Komatsushima, Aoba-ku, Sendai 981-8558, Japan

E-mail: syu-kan@tohoku-pharm.ac.jp

Key words: albumin, sorafenib, cytotoxicity, hepatoma, prostate cancer, warfarin

\section{Introduction}

Albumin is the most abundant plasma protein synthesized primarily by liver cells. It is important in regulating blood volume by maintaining the oncotic pressure and also serving as a carrier for various molecules of low water solubility and transport drugs. This highly soluble protein is present in human plasma at a normal concentration between 35 and $50 \mathrm{~g} / 1$ (1). The half-life of albumin is approximately 19 days and accounts for at least $10 \%$ of liver protein synthesis. This suggests that $10-15 \mathrm{~g}$ of albumin is produced per day in healthy subjects (2). Serum albumin concentrations below the normal range occur in a variety of disorders. Among these disorders are those associated with malnutrition and malabsorption, where protein is either not consumed in the diet or is lost through the gastrointestinal tract (3). Subsequently, a decrease in albumin concentration is frequently observed in patients with liver disorders (4), and plasma albumin is also reduced in cancer (5) and sepsis (6). Specifically, in nephrotic syndrome or protein-losing gastroenteropathy, plasma albumin is highly reduced to $<20 \mathrm{~g} / \mathrm{l}$ due to excessive albumin loss in urine or incomplete albumin synthesis (7). Thus, lower serum albumin (i.e., hypoalbuminaemia) is likely to be affected by a higher binding affinity of certain drugs with albumin.

Sorafenib, 4-pyridine 2-carboxylic acid methylamide 4-methylbenzenesulfonate, is an orally administered multikinase inhibitor that exhibits anti-angiogenic and anti-tumor activity (8). This activity is caused by targets in the kinase domains of vascularendothelial growth factor(VEGF), plateletderived growth factor (PDGF) and inhibition signaling through the RAF kinases, including Raf-1 and Raf-B, or RAF/mitogenactivated protein (MAP)/extracellular signal-regulated kinase (ERK) kinase (MEK)/ERK (RAF/MEK/ERK) cascade $(9,10)$. Sorafenib as a single agent has demonstrated preclinical and clinical activity against several types of tumorxx (11-15). Sorafenib is known to bind to protein $(>99.5 \%)$ and has a low hepatic extraction ratio, suggesting that protein binding is important in sorafenib pharmacokinetic variability (16). Thus, variations in sorafenib binding may contribute to the variability in sorafenib exposure. A recent study reported the characterization of in vitro sorafenib binding properties to albumin and the effect of albuminemia on sorafenib clearance and its disposition in cancer patients (17). Similar reports have shown that sorafenib is highly protein-bound in human plasma 
with a higher affinity towards albumin and that limited free drugs may play a role in its borderline clinical activity (18).

In this study, we examined the effect of both extracellular (exogenous) and tissue (endogenous) albumin on sorafenibinduced cytotoxicity using two major in vitro culture cell lines, human hepatoma Huh-7 cells and androgen-independent prostate cancer PC-3 cells. In addition, we evaluated the cytotoxic effects of drug interaction with sorafenib and warfarin, both of which exhibited a high affinity for albumin. This is the first report to show that predominantly exogenous albumin inhibits sorafenib-induced cytotoxicity resulting from its extracellular binding properties. These data may be useful in the clinical application of sorafenib.

\section{Materials and methods}

Materials and cell culture. Sorafenib was purchased from Toronto Research Chemicals Incorporated (Ontario, Canada). Sorafenib was dissolved in dimethyl sulfoxide (DMSO) and final concentrations were prepared on the day of use from a stock solution. A concentration range of 0.1 to $60 \mu \mathrm{M}$ was typically used in the different experiments. Albumin, from human serum (catalog no. A1653, Sigma, St. Louis, MO, USA) and all other reagents, unless otherwise stated, were of the highest grade available and were purchased from either Sigma or Wako Pure Chemical Industries, Ltd. (Osaka, Japan). Cells were supplied by the Cell Resource Center for Biomedical Research, Tohoku University (Sendai, Japan). The cells were routinely cultured using standard methods as described in our previous report (19) Research protocols were approved by the Ethics Committees of Tohoku Pharmaceutical University.

MTT assay. Cytotoxicity was assessed by the MTT [3-(4,5-dimethylthiazol-2-yl)-2,5-diphenyl tetrazolium bromide] assay, a modification of our previously described method (20). Briefly, cells were seeded at $5 \times 10^{3}$ in 96 -well plates and cultured overnight. The cells were washed with serum-free medium. The medium was removed and replaced with or without $4 \%$ albumin contents in serum-free media. The cells were then incubated with sorafenib for $48 \mathrm{~h}$, followed by the addition of $10 \mu \mathrm{l} \mathrm{MTT}(5 \mathrm{mg} / \mathrm{ml}$ saline) to each well. Samples were incubated for $90 \mathrm{~min}$ at $37^{\circ} \mathrm{C}$, the supernatant was aspirated, and the cells were lysed and solubilized by the addition of $100 \mu \mathrm{l}$ of $0.04 \mathrm{~N} \mathrm{HCl}$ in isopropanol. The absorbance of each well was determined at $590 \mathrm{~nm}$ using an Inter-med model NJ-2300 Microplate Reader. The control cells were treated with $0.5 \%$ DMSO (sorafenib vehicle). Cell viability was calculated using the formula: absorbance in treated sample/absorbance in control x100 (\%).

Western blotting. The effects of signal transduction by sorafenib or confirmation of the transfected assay were estimated by western blotting (21). Briefly, the cells were washed with PBS and lysed in CelLytic M (Sigma), according to the manufacturer's instructions. Samples of each protein $(30 \mu \mathrm{g})$ were loaded onto a $10 \%$ SDS-polyacrylamide gel. After electrophoresis, the protein was transferred to a polyvinylidene difluoride (PVDF) membrane. The protein was blocked with blocking solution (25 mM Tris- $\mathrm{HCl}, \mathrm{pH} 7.4$, $137 \mathrm{mM} \mathrm{NaCl}, 2.68 \mathrm{mM} \mathrm{KCl}$ and 5\% skim milk) for $4 \mathrm{~h}$ and reacted with antibody overnight at $4^{\circ} \mathrm{C}$. The membrane was then washed with blocking solution without skimmed milk, and incubated with horseradish peroxidase-linked secondary antibody for $1 \mathrm{~h}$. After another wash, the protein levels were analyzed by enhanced chemiluminescence with an ECL plus western blotting detection system (Amersham, Arlington Heights, IL, USA). The primary antibodies used were: VEGF (Calbiochem, Darmstadt, Germany) and Raf-B (Santa Cruz Biotechnology, Inc., Santa Cruz, CA, USA). Albumin and any other antibodies were from Cell Signaling (Beverly, MA, USA).

Transfection studies. siRNA-albumin (siALB) and siRNAcontrol as non-targeting siRNA (Negative control: Neg) were transfected into Huh-7 cells using HyperFect transfection reagent (Qiagen, Valencia, CA, USA) according to the manufacturer's instructions. A non-targeting siRNA was used as a control for the non-sequence-specific effects of the transfected siRNAs. The siRNAs (Qiagen) used were siALB from GeneSolution siRNA (catalog no. 1027416) and negative control from AllStars negative control siRNA (catalog no. 1027281). Briefly, Huh-7 $\left(1 \times 10^{5}\right)$ cells containing each siRNA (final concentration, $40 \mathrm{nM}$ ) and HyperFect reagent were incubated for $24 \mathrm{~h}$, assessed by western blotting using the expression of $\beta$-actin as the control and their cytotoxic effects were evaluated by sorafenib.

The albumin was overexpressed using the vector established in our previous study (19). PC-3 cells were transfected with pcDNA 3.1 plasmid DNA alone (empty) or containing Albumin cDNA (ALB) using Lipofectamine ${ }^{\mathrm{TM}}$ LTX reagent (Invitrogen, Carlsbad, CA, USA) according to the manufacturer's instructions. After being cultured for $24 \mathrm{~h}$ without antibiotics, the transfected cells were examined for western blotting using the expression of $\beta$-actin as the control or using the cytotoxicity assay.

Statistical analysis. Statistical analysis of the results was performed using a one-way analysis of variance (ANOVA) followed by the Williams' type multiple comparison test or a Bonferroni test among multiple groups. $\mathrm{P}<0.05$ was considered statistically significant.

\section{Results}

Comparison of the effect of cells supplemented with or without albumin in serum-free media on sorafenib-induced cytotoxicity. Albumin is contained in the serum of culture media. To explore the essentially exogenous albumin by sorafenib-induced cytotoxicity, we examined the human hepatoma Huh-7 or prostate cancer PC-3 cells, supplemented with or without albumin in serum-free media. To perform the assessment of exogenous albumin in this assay, a concentration of $4 \%$ of normal physiologically serum content was used. The concentration of sorafenib up to $1 \mu \mathrm{M}$ exhibited no cytotoxic effect on the two cell lines whether or not they were albuminsupplemented or serum-free (Fig. 1A and B). The cell lines were relatively robust to cell stress since when the serum was removed from the culture media, no spontaneous apoptotic effects were observed in the culture for $48 \mathrm{~h}$ (data not shown). In serum-free conditions of $>1 \mu \mathrm{M}$, sorafenib showed 

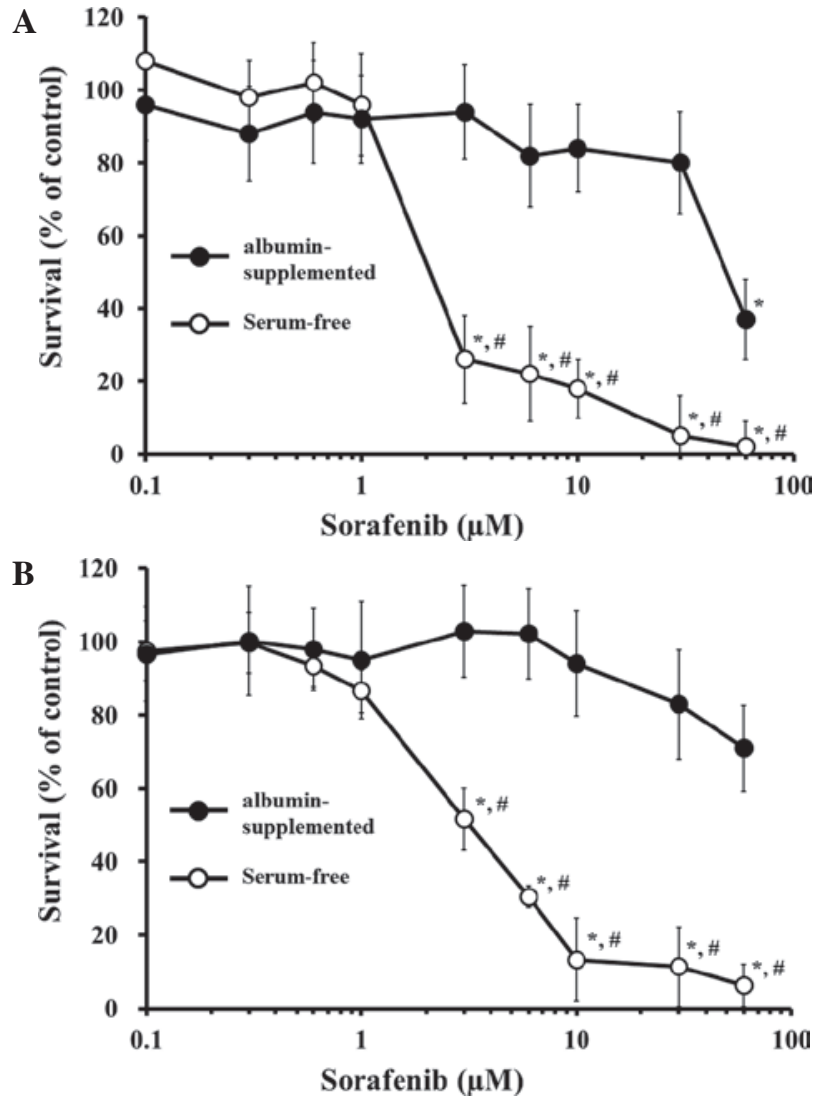

Figure 1. Comparison of albumin-supplemented and serum-free media on sorafenib-induced cytotoxicity in (A) human hepatoma Huh-7 cells, or (B) on human prostate cancer PC-3 cells. Each cell line was seeded in a 96-well culture plate overnight under normal culture conditions. The cells were washed in serum-free medium prior to incubation with sorafenib and used for serum-free conditions in this study. Albumin-supplemented conditions were prepared by the addition of albumin (final concentration of albumin at 4\%) in serum-free media. The medium was replaced with serum-free conditions and incubated with sorafenib for $48 \mathrm{~h}$. Cytotoxicity was assessed using the MTT assay and survival (\%) was calculated relative to the control (sorafenib vehicle) in each condition. Results are the means \pm SEM of three individual studies. " $p<0.05$ or $" \mathrm{p}<0.05$ compared with the control group, or albumin-supplemented culture condition with each indicated sorafenib incubation, respectively.

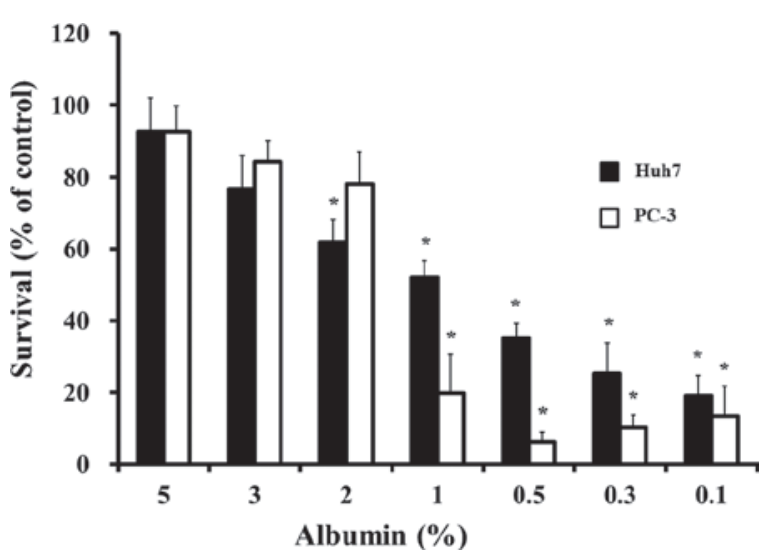

Figure 2. Concentration-dependent effect of exogenous albumin on $10 \mu \mathrm{M}$ sorafenib-induced cytotoxicity in Huh-7 or PC-3 cells. The albumin concentration was changed from 0.1 to $5 \%$ in each cell and incubated with sorafenib for $48 \mathrm{~h}$. Cytotoxicity was assessed using the MTT assay and survival (\%) was calculated relative to the control (sorafenib vehicle) in each condition. Results are the means \pm SEM of three individual studies. ${ }^{*} \mathrm{p}<0.05$ compared with the control group (sorafenib vehicle) on indicated albuminsupplemented culture condition.
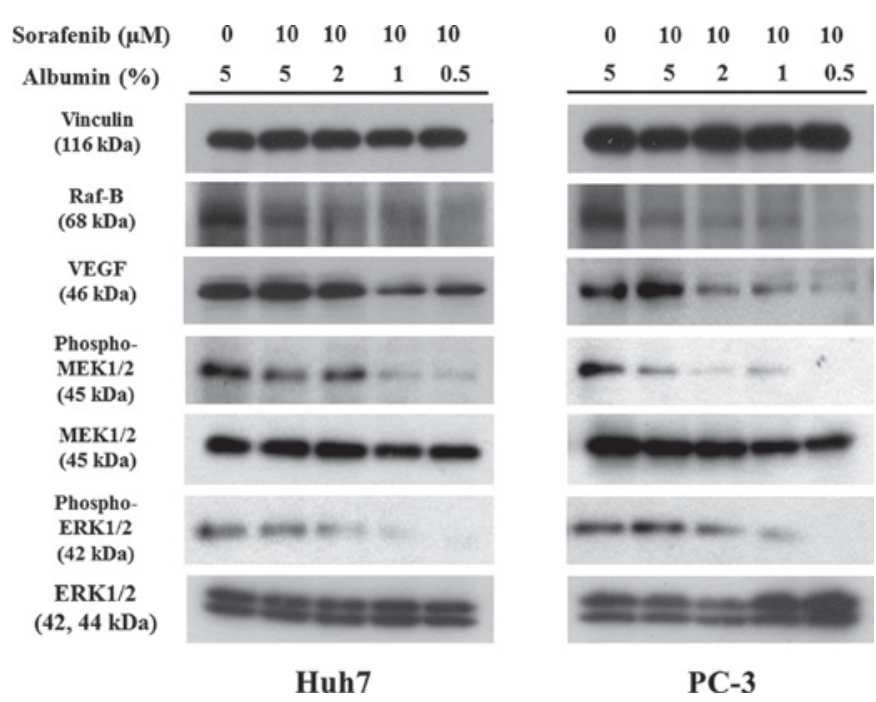

Figure 3. Western blot analysis of sorafenib-induced changes in the level of pharmacological signal proteins. Cells were incubated with $10 \mu \mathrm{M}$ sorafenib for $4 \mathrm{~h}$ on each indicated concentration of albumin-supplemented condition in Huh-7 or PC-3 cells. Expression of indicated proteins was then analyzed by western blotting using the expression of vinculin, MEK1/2 and ERK1/2 as the controls. Experiments shown are representative of a minimum of three separate experiments.

a significant concentration-dependent cytotoxic effect in the two cells. By contrast, albumin-supplemented conditions potently inhibited the cytotoxic effect of sorafenib up to 10 or $30 \mu \mathrm{M}$ in Huh-7 or PC-3 cells, respectively. The calculated $50 \%$ cell growth inhibition $\left(\mathrm{IC}_{50}\right)$ of serum-free or albuminsupplemented conditions in Huh-7 was 1.628 or $44.62 \mu \mathrm{M}$, and 3.319 or $153.7 \mu \mathrm{M}$, respectively, in PC-3. Thus, the presence of exogenous albumin markedly blocked the sorafenib-induced cytotoxicity in the two cells.

Concentration-dependent effects of exogenous albumin on sorafenib-induced cytotoxicity. We examined the concentration-dependent effect of exogenous albumin on $10 \mu \mathrm{M}$ sorafenib-induced cytotoxicity in Huh-7 or PC-3 cells. Exogenous lower albumin $<2 \%$ in Huh-7, or $1 \%$ in PC-3, respectively, exhibited an increased concentration-dependent cytotoxic effect after $10 \mu \mathrm{M}$ sorafenib was added in each of the cells (Fig. 2). Western blotting was used to confirm the lower albumin concentration on the pharmacological pathway of signal transduction by sorafenib in the two cells (Fig. 3). No change was observed in the expression of vinculin as the control or total MEK1/2 or ERK1/2 proteins as each signal control. However, previous reported changes of signal proteins, such as Raf-B, VEGF and the phosphorylation of MEK1/2 or ERK1/2, following incubation with $10 \mu \mathrm{M}$ sorafenib, correlated with the decrease in co-incubation with albumin in a concentration-dependent manner. Accordingly, these changes suggest that the reduction of cell survival and the concentration of exogenous lower albumin may drive the effect of sorafenib.

Drug interaction with warfarin and sorafenib on cell survival reduction. Warfarin, a representative coumarin anticoagulant is known for its interaction with numerous drugs. This drug 


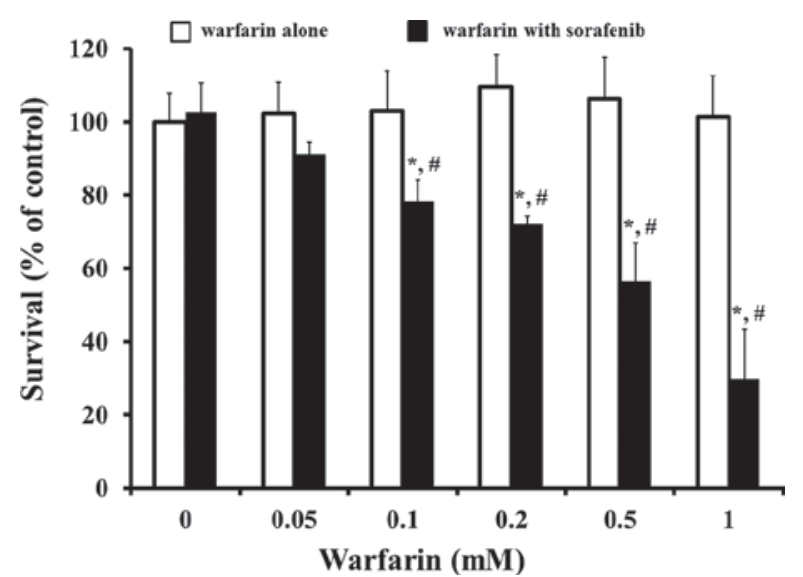

Figure 4. Effects of warfarin, a representative coumarin anticoagulant on sorafenib-induced cytotoxicity on Huh-7 cells. Warfarin at $0.05-1 \mathrm{mM}$ was co-incubated with $3 \mu \mathrm{M}$ sorafenib and cultured for $48 \mathrm{~h}$ in Huh-7 cells on albumin-supplemented conditions. Cytotoxicity was assessed using the MTT assay and survival (\%) was calculated relative to the control (sorafenib vehicle) in each condition. Results are the means \pm SEM of three individual studies. ${ }^{*}<<0.05$ or ${ }^{\#} \mathrm{p}<0.05$ compared to the control group, or each indicated concentration of single incubation with warfarin group, respectively.

has potent binding activity with albumin. As stated above, the effect of sorafenib pertains to exogenous albumin. Thus, we examined the effect of warfarin on $3 \mu \mathrm{M}$ sorafenb-induced cytotoxicity in Huh-7 cells with albumin-supplemented conditions (Fig. 4). A single incubation with warfarin up to $1 \mathrm{mM}$ did not show any cytotoxic effect on Huh-7 during the $48 \mathrm{~h}$ culture. Co-incubation with warfarin of $>0.05 \mathrm{mM}$ and sorafenib at $3 \mu \mathrm{M}$ showed a significant warfarin concentration-dependent increase in the reduction of cell survival. Similarly, warfarin was found to potentiate the cytotoxic effect of sorafenib in PC-3 cells (data not shown).

Effects of endogenous albumin on sorafenib-induced cytotoxicity. In the physiological conditions, albumin exists in extracellular (exogenous) form as serum and in intracellular form on tissues (endogenous). Furthermore, we investigated the effect of endogenous albumin expression on sorafenib-induced cytotoxicity using a siRNA knock-down system in Huh-7 cells or the transfected expression vector assay in PC-3 cells (Fig. 4A and B). In the Huh-7 hepatoma cells, the constantly expressed albumin protein was derived from liver tissues, and the albumin expression was almost completely knocked down by transfection with siALB (Fig. 5A). Incubation with sorafenib at 0.3 to $30 \mu \mathrm{M}$ has shown a concentration dependent cell survival reduction in mock (not transfected with siRNA), siNeg (transfected with non-specific siRNA as negative control) and siALB Huh-7 cells. However, no significant changes occurred in the transfected cell conditions, with the exception of incubation with $1 \mu \mathrm{M}$ sorafenib in the siALB cells. Prostate cancer as PC-3 did not entirely express the albumin protein in the usual culture state, whereas the introduction of the albumin expression vector apparently overexpressed albumin in this study (Fig. 5B). Similarly, these cells exhibited concentrationdependent cytotoxic effects by sorafenib, but there were no differences regarding whether or not they were transfected with the albumin vector. These data indicated that tissue albumin rarely affects sorafenib-induced cytotoxicity.
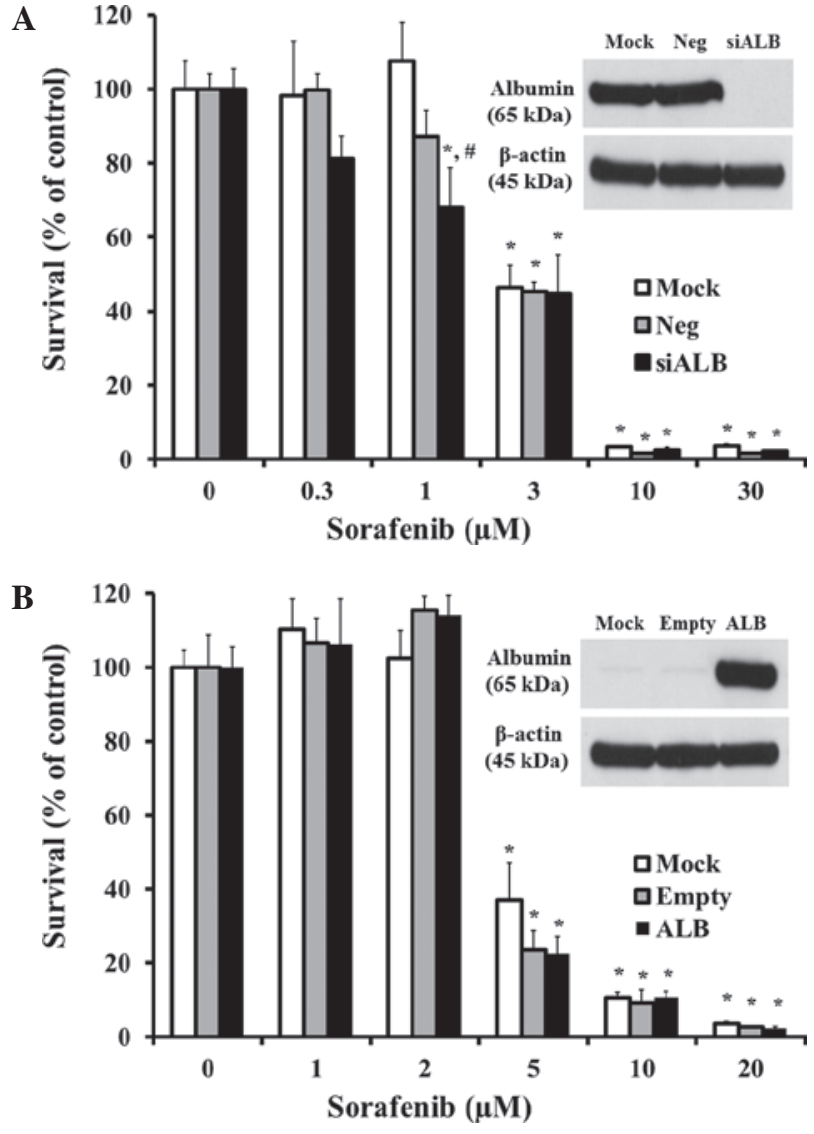

Figure 5. Effects of tissue (endogenous) albumin on sorafenib-induced cytotoxicity using (A) a siRNA knock-down system in Huh-7 cells or (B) a transfected expression vector assay in PC-3 cells. Each transfection assay was described in the Materials and methods. Expression of albumin protein was analyzed by western blotting using the expression of $\beta$-actin as the control. Experiments shown are representative of a minimum of three separate experiments. Results are the means \pm SEM of three individual studies. ${ }^{*} \mathrm{p}<0.05$ or ${ }^{\#} \mathrm{p}<0.05$ compared to the control and mock groups, respectively.

\section{Discussion}

Sorafenib is known to bind to albumin resulting in a strong effect on sorafenib clearance in albuminemia and therefore on its disposition in adult cancer patients with advanced solid tumors $(17,18)$. In several pathological states, endogenous ligands may accumulate to relatively high concentrations able to displace drugs highly bound to albumin, resulting in a significant increase in the unbound fraction of drugs (22). Patients with advanced solid tumors frequently exhibit denutrition and they have severe renal or hepatic impairment. Under those circumstances, hypoalbuminemia, hypertriglyceridemia or hyperbilirubinemia may occur. Therefore, an increase in sorafenib unbound fraction resulting in an enhanced clearance should be expected. This study demonstrates that exogenous albumin inhibits sorafenib-induced cytotoxicity in human cancer cell lines. This result suggests that in the case of serious side effects, depending on the higher plasma concentration of sorafenib in cancer patients following sorafenib treatments, exogenous albumin may be used as an antidote drug for overdose of sorafenib. In serum-free media, albumin is often used instead of fetal bovine serum in the cell culture media, improving the performance of a wide range of cell 
types, including stem and primary cells (23). Thus, albumin is added to the cell culture media as a supplement to increase the growth and productivity of cells (24). Our in vitro study may not completely reflect cell growth, but the albuminsupplemented groups did not show any change, compared with the usual culture conditions in the experimental period.

The cytotoxic effect of sorafenib has shown a statistically significant increase below the concentration of $2 \%$ albumin compared with the $5 \%$ albumin-supplemented conditions (Fig. 2). In clinical cases, however, a $2 \%$ albumin concentration in plasma is regarded as a serious pathological event. Despite the enhanced effect of a lower concentration of albumin in our experimental study, the use of sorafenib may be used in cancer patients with albuminemia. A decrease in the expression in Raf-B and the phosphorylation of MEK by sorafenib showed no change for either the 5 or $2 \%$ albumin concentration in the two cells (Fig. 3). These results suggest that sorafenib inhibits kinase activation without exhibiting significant cytotoxic effects. In contrast to standard antineoplastics, sorafenib was also shown to be suitable for long-term administration due to its good safety profile (25). Currently, sorafenib is approved for the treatment of patients with advanced renal cell carcinoma and those with hepatocellular carcinoma. In this study, we used two distinct human cancer cells, hepatoma and prostate cancer. Patients with metastatic androgen-independent prostate cancer have a poor prognosis with few therapeutic options, all of which are palliative. The effect of sorafenib on PC-3, a hormone refractory, metastatic prostate carcinoma cell line was also examined. In their study, Ullén et al indicated that sorafenib induced apoptosis and autophagy in two hormone refractory prostate cancer cells in vitro, including PC-3 (26). Our results partly supported previous data which showed that sorafenib can be widely applied in other tumor types. As shown in Fig. 4, co-incubation with warfarin enhanced the sorafenibinduced cytotoxicity; however, the experimental concentration of warfarin used in this study was much higher than that of the clinical plasma concentration at almost $567.6 \pm 123.3 \mathrm{ng} / \mathrm{ml}$ $(1.72 \pm 0.37 \mu \mathrm{M})(27)$. Although no serious side effects of the interaction between sorafenib and warfarin have been known to occur in clinical patients, the combination should be used with care. Of note, combined use of sorafenib with warfarin is written as 'attention' on the information provided in the NEXAVAR $^{\circledR}$ (sorafenib) package insert.

Drug distribution is a function of both plasma protein and tissue protein bindings. One of the physiological actions of albumin involves transporting drugs. If tissue albumin attracts or blocks sorafenib in its high affinity towards albumin, it may serve as a good target or delivery carrier for cancer chemotherapy. Thus, we hypothesized that change in tissue albumin may affect sorafenib-induced cytotoxicity. In contrast to our expectation, sorafenib-induced cytotoxicity has changed little in tissue albumin, regardless of whether or not albumin was overexpressed or knocked-down in experimental cells (Fig. 5A and B). Currently, no reports are available examining the cancer chemotherapeutic drug effects of the change of tissue albumin. Thus, the cytotoxic effect of sorafenib is not likely to be correlated with the expression of tissue albumin as existing cancer chemotherapeutic drugs.

In conclusion, sorafenib-induced cytotoxicity is inhibited by extracellular albumin but not tissue albumin in human cancer cell lines. These mechanisms depend on the high-bound properties of sorafenib and exogenous albumin. Our results suggest that in case of serious side effects in cancer patients receiving sorafenib treatments, exogenous albumin may be used as an antidote drug for overdose of sorafenib. However, even then care should be taken when adminstering a combined use of drugs with high-bound affinity towards albumin, such as warfarin, in cancer patients with albuminemia. Therefore, our findings may be useful in the cancer therapeutic strategy by sorafenib.

\section{References}

1. Peters T (ed): All About Albumin: Biochemistry, Genetics, and Medical Applications. Academic Press, San Diego, 1996.

2. Ballmer PE, McNurlan MA, Milne E, Heys SD, Buchan V, Calder AG and Garlick PJ: Measurement of albumin synthesis in humans: a new approach employing stable isotopes. Am J Physiol 259: E797-E803, 1990.

3. Waldmann TA: Protein-losing enteropathy and kinetic studies of plasma protein metabolism. Semin Nucl Med 2: 251-263, 1972.

4. Ballmer PE, Walshe D, McNurlan MA, Watson H, Brunt PW and Garlick PJ: Albumin synthesis rates in cirrhosis: correlation with Child-Turcotte classification. Hepatology 18: 292-297, 1993.

5. Pasanisi F, Orban A, Scalfi L, Alfonsi L, Santarpia L, Zurlo E, Celona A, Potenza A and Contaldo F: Predictors of survival in terminal-cancer patients with irreversible bowel obstruction receiving home parenteral nutrition. Nutrition 17: 581-584, 2001.

6. Ruot B, Breuillé D, Rambourdin F, Bayle G, Capitan P and Obled C: Synthesis rate of plasma albumin is a good indicator of liver albumin synthesis in sepsis. Am J Physiol Endocrinol Metab 279: E244-E251, 2000.

7. Ballmer PE: Causes and mechanisms of hypoalbuminaemia. Clin Nutr 20: 271-273, 2001.

8. Wilhelm S, Carter C, Lynch M, Lowinger T, Dumas J, Smith RA, Schwartz B, Simantov R and Kelley S: Discovery and development of sorafenib: a multikinase inhibitor for treating cancer. Nat Rev Drug Discov 5: 835-844, 2006.

9. Wilhelm SM, Carter C, Tang L, et al: BAY 43-9006 exhibits broad spectrum oral antitumor activity and targets the RAF/ MEK/ERK pathway and receptor tyrosine kinases involved in tumor progression and angiogenesis. Cancer Res 64: 7099-7109, 2004.

10. Liu L, Cao Y, Chen C, Zhang X, McNabola A, Wilkie D, Wilhelm S, Lynch M and Carter C: Sorafenib blocks the RAF/ MEK/ERK pathway, inhibits tumor angiogenesis, and induces tumor cell apoptosis in hepatocellular carcinoma model PLC/ PRF/5. Cancer Res 66: 11851-11858, 2006.

11. Escudier B, Eisen T, Stadler WM, et al: Sorafenib for treatment of renal cell carcinoma: final efficacy and safety results of the phase III treatment approaches in renal cancer global evaluation trial. J Clin Oncol 27: 3312-3318, 2009.

12. Llovet JM, Ricci S, Mazzaferro V, et al: Sorafenib in advanced hepatocellular carcinoma. N Engl J Med 359: 378-390, 2008.

13. Wilhelm SM, Adnane L, Newell P, Villanueva A, Llovet JM and Lynch M: Preclinical overview of sorafenib, a multikinase inhibitor that targets both Raf and VEGF and PDGF receptor tyrosine kinase signaling. Mol Cancer Ther 7: 3129-3140, 2008.

14. Kloos RT, Ringel MD, Knopp MV, et al: Phase II trial of sorafenib in metastatic thyroid cancer. J Clin Oncol 27: 1675-1684, 2009.

15. Dahut WL, Scripture C, Posadas E, et al: A phase II clinical trial of sorafenib in androgen-independent prostate cancer. Clin Cancer Res 14: 209-214, 2008.

16. Jain L, Woo S, Gardner ER, Dahut WL, Kohn EC, Kummar S, Mould DR, Giaccone G, Yarchoan R, Venitz J and Figg WD: Population pharmacokinetic analysis of sorafenib in patients with solid tumours. Br J Clin Pharmacol 72: 294-305, 2011.

17. Tod M, Mir O, Bancelin N, et al: Functional and clinical evidence of the influence of sorafenib binding to albumin on sorafenib disposition in adult cancer patients. Pharm Res 28: 3199-3207, 2011.

18. Villarroel MC, Pratz KW, Xu L, Wright JJ, Smith BD and Rudek MA: Plasma protein binding of sorafenib, a multi kinase inhibitor: in vitro and in cancer patients. Invest New Drugs: Nov. 17, 2011 (E-pub ahead of print) 
19. Kanno S, Kurauchi K, Tomizawa A, Yomogida S and Ishikawa M Albumin modulates docosahexaenoic acid-induced cytotoxicity in human hepatocellular carcinoma cell lines. Toxicol Lett 200: $154-161,2011$.

20. Kanno S, Higurashi A, Watanabe Y, Shouji A, Asou K and Ishikawa M: Susceptibility to cytosine arabinoside (Ara-C)induced cytotoxicity in human leukemia cell lines. Toxicol Lett 152: 149-158, 2004.

21. Kanno SI, Maeda N, Tomizawa A, Yomogida S, Katoh T and Ishikawa M: Involvement of $\mathrm{p} 21^{\text {waf } 1 / \mathrm{cip} 1}$ expression in the cytotoxicity of the potent histone deacetylase inhibitor spiruchostatin B towards susceptible NALM-6 human B cell leukemia cells. Int J Oncol 40: 1391-1396, 2012.

22. Tesseromatis $\mathrm{C}$ and Alevizou A: The role of the protein-binding on the mode of drug action as well the interactions with other drugs. Eur J Drug Metab Pharmacokinet 33: 225-230, 2008.

23. Mather JP: Making informed choices: medium, serum, and serum-free medium. How to choose the appropriate medium and culture system for the model you wish to create. Methods Cell Biol 57: 19-30, 1998.
24. Fanali G, di Masi A, Trezza V, Marino M, Fasano M and Ascenzi P: Human serum albumin: from bench to bedside. Mol Aspects Med 33: 209-290, 2012.

25. Blanchet B, Billemont B, Barete S, Garrigue H, Cabanes L, Coriat R, Francès C, Knebelmann B and Goldwasser F: Toxicity of sorafenib: clinical and molecular aspects. Expert Opin Drug Saf 9: 275-287, 2010.

26. Ullén A, Farnebo M, Thyrell L, Mahmoudi S, Kharaziha P, Lennartsson L, Grandér D, Panaretakis T and Nilsson S: Sorafenib induces apoptosis and autophagy in prostate cancer cells in vitro. Int J Oncol 37: 15-20, 2010.

27. Sun S, Wang M, Su L, Li J, Li H and Gu D: Study on warfarin plasma concentration and its correlation with international normalized ratio. J Pharm Biomed Anal 42: 218-222, 2006. 